\title{
Comunicação
}

[Communication]

\section{Preservação do sistema genital de chinchila (Chinchilla lanigera) para avaliação em microscopia de luz}

\author{
[Preservation of chinchilla genital system (Chinchilla lanigera) for microscopic evaluation]

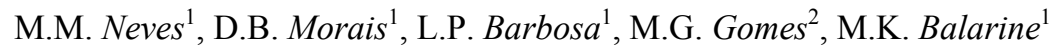 \\ ${ }^{1}$ Centro Universitário do Leste de Minas Gerais, Ipatinga, MG \\ ${ }^{2}$ Escola de Medicina - UFMG, Belo Horizonte, MG
}

Os procedimentos de fixação e inclusão de tecidos ou células apresentam pontos críticos na preservação da arquitetura histológica. As células e seus constituintes quando não fixadas corretamente mostram distorção e retração que dificultam sua avaliação (Fox et al., 1985). Por essa razão, a busca por adequada solução fixadora é importante para o estudo histológico de diferentes tecidos biológicos. O tempo de fixação, o tamanho da amostra e a capacidade de penetração do fixador são pontos importantes para a obtenção de bom material para histomorfologia, histoquímica e avaliação imunológica (Salmito-Vanderley et al., 2002).

A escolha de um fixador que melhor defina as estruturas celulares e teciduais do sistema genital de chinchilas tem como vantagem proporcionar maior confiabilidade nas análises morfológicas dos órgãos, tanto em genitálias gestantes quanto não-gestantes, principalmente quando se trabalha com peças anatômicas de difícil aquisição, como é o caso dessa espécie animal, garantindo melhor preservação das mesmas para futuras avaliações.

O objetivo deste trabalho foi estabelecer o melhor fixador para ovários, tubas uterinas, útero, cérvice e vagina de chinchilas.

Duas chinchilas adultas, oriundas de criatório comercial, foram sacrificadas utilizando-se xilazina, diazepan e quetamina para sedação e anestesia (Morgan et al., 1981), seguido de cloreto de potássio, procedendo-se à imediata evisceração. $\mathrm{O}$ sistema genital feminino foi avaliado macroscopicamente quanto ao seu estado geral e, em seguida, foram coletados os ovários e fragmentos das tubas uterinas, cornos uterinos, cérvice e vagina.

Os órgãos foram fixados nos tempos de 4, 12 e 18 horas utilizando-se formol a 10\% tamponado e solução saturada de Bouin. Depois de fixados, os espécimes foram desidratados com passagens sucessivas em soluções de álcool em concentrações crescentes $(70 \%, 80 \%, 90 \%$ e absoluto), diafanizados em xilol, incluídos em parafina e blocados. Foram feitos cortes de $4 \mu \mathrm{m}$ de espessura em micrótomo e posterior montagem das lâminas, corando-as com $\mathrm{HE}$ (Luna, 1968).

$\mathrm{Na}$ avaliação microscópica, consideram-se: Iretração do tecido - ausente ou presente (pequena, moderada ou grande); II- definição das estruturas em acidófilas (A) e basófilas (B) visualização boa ou ideal; e III- integridade celular com visualização do limite entre as células e as estruturas morfocitológicas preservada, pouco preservada e não preservada. Os resultados são mostrados na Tab. 1 .

No protocolo de fixação que utilizou formol a $10 \%$ tamponado, a vagina foi o órgão mais susceptível a dissociações das fibras conjuntivas. A definição de estruturas acidófilas e basófilas foi satisfatória para todos os órgãos, e a integridade celular apresentou-se satisfatória nos ovários, tubas uterinas e útero, visualizando-se estruturas citológicas como núcleos e membranas celulares.

Recebido em 9 de setembro de 2005

Aceito em 16 de setembro de 2006

E-mail: mmachadoneves@yahoo.com.br 
Tabela 1. Avaliação microscópica de órgãos colhidos de chinchilas, fêmeas, segundo o fixador

\begin{tabular}{|c|c|c|c|c|}
\hline Fixador & Ovário & Tubas uterinas & Útero/ cérvice & Vagina \\
\hline $\begin{array}{l}\text { Formol a } 10 \% \\
\text { tamponado }\end{array}$ & $\begin{array}{l}\text { I - Ausente } \\
\text { II -A/B; Visualização } \\
\text { boa } \\
\text { III - Preservada - limites } \\
\text { definidos }\end{array}$ & $\begin{array}{l}\text { I - Ausente } \\
\text { II - A/B; Visualização } \\
\text { boa } \\
\text { III - Preservada - limites } \\
\text { definidos }\end{array}$ & $\begin{array}{l}\text { I - Presente: pequena } \\
\text { II - A/B; Visualização } \\
\text { boa } \\
\text { III - Preservada }\end{array}$ & $\begin{array}{l}\text { I - Presente: grande } \\
\text { II - A/B } \\
\text { III - Pouco preservada }\end{array}$ \\
\hline $\begin{array}{l}\text { Bouin } \\
4 \text { horas }\end{array}$ & $\begin{array}{l}\text { I - Presente: pequena } \\
\text { II - A/B } \\
\text { III - Preservada }\end{array}$ & $\begin{array}{l}\text { I - Ausente } \\
\text { II - A/B } \\
\text { III - Preservada }\end{array}$ & $\begin{array}{l}\text { I - Presente: pequena } \\
\text { II - B } \\
\text { III - Pouco preservada }\end{array}$ & $\begin{array}{l}\text { I - Presente: pequena } \\
\text { II - A/B } \\
\text { III - Pouco preservada }\end{array}$ \\
\hline $\begin{array}{l}\text { Bouin } \\
12 \text { horas }\end{array}$ & $\begin{array}{l}\text { I - Presente: pequena. } \\
\text { II - B } \\
\text { III - Preservada, limites } \\
\text { definidos }\end{array}$ & $\begin{array}{l}\text { I - Presente: moderada. } \\
\text { II - A/B Visualização } \\
\text { boa } \\
\text { III - Preservada, limites } \\
\text { definidos }\end{array}$ & $\begin{array}{l}\text { I - Presente: pequena } \\
\text { II - A/B Visualização } \\
\text { boa } \\
\text { III - Preservada, limites } \\
\text { definidos }\end{array}$ & $\begin{array}{l}\text { I - Presente: grande } \\
\text { II - A/B } \\
\text { III - Preservada }\end{array}$ \\
\hline $\begin{array}{l}\text { Bouin } \\
18 \text { horas }\end{array}$ & $\begin{array}{l}\text { I - Ausente. } \\
\text { II - A/B. Visualização } \\
\text { boa } \\
\text { III - Pouco preservada }\end{array}$ & Material perdido & $\begin{array}{l}\text { I - Presente: moderada } \\
\text { II - B } \\
\text { III - Preservada }\end{array}$ & $\begin{array}{l}\text { I - Presente: pequena } \\
\text { II - A/B } \\
\text { III - Preservada, limites } \\
\text { definidos }\end{array}$ \\
\hline
\end{tabular}

I: retração do tecido; II: definição das estruturas acidófilas (A) e basófilas (B); III: integridade celular.

A solução de Bouin mostrou-se boa fixadora. Para a retração dos tecidos, o tempo de fixação não foi crítico para ovários, tubas uterinas e útero, diferente da vagina que apresentou grande dissociação de fibras quando fixadas nos tempos superiores a quatro horas. Com relação à visualização das estruturas acidófilas e basófilas, independente do tempo de fixação, as tubas uterinas e a vagina não sofreram alterações significativas. Os ovários e o útero, nos tempos de 4 e 18 horas, mostraram-se mais basófilos. A integridade celular também não foi influenciada pelo tempo para tuba uterina, sendo o tempo de 12 horas de fixação o ideal para observação de núcleos e membranas celulares.
A solução saturada de Bouin com 12 horas de fixação mostrou-se mais adequada para fixação do sistema genital feminino de chinchilas, promovendo pouca retração dos tecidos e preservação das estruturas morfocitológicas, quando comparada com os demais tempos. O formol a $10 \%$ também se mostrou eficiente quanto à preservação dos tecidos, sendo recomendado quando da impossibilidade de se usar o Bouin.

Palavras-chave: chinchila, Chinchilla lanigera, sistema genital, fêmea, fixador, microscopia de luz

\begin{abstract}
The preservation of chinchilla genital organs using a fixed solution of paraformaldehyde $10 \%$ buffered and a saturated solution of Bouin during 4, 12 and 18 hours of fixation, inclusion in paraffin and staining with hematoxylin-eosin was evaluated. The Bouin solution with 12 hours of fixation was the best protocol of fixation for the ovaries, oviduct, uterus and vagina, resulting in little tissue retraction and better cellular integration when compared to the other fixing times (4 and 18 hours). The fixation with paraformaldehyde showed good results of tissues fixation. Chinchilla genital organs can be preserved with paraformaldehyde $10 \%$ buffered and Bouin solution using 12 hours of fixation.
\end{abstract}

Keywords: chinchilla, Chinchilla lanigera, female genital system, fixing solution, light microscopy

\section{REFERÊNCIAS BIBLIOGRÁFICAS}

FOX, C.H.; JOHNSON, F.B.; WHITINNG, J. et al. Formaldehyde fixation. J. Histochem. Cytochem., v.33, p. $845-853,1985$.

LUNA, L.G. Manual of histologic staining methods of the Armed Forces Institute of Pathology. 3.ed. New York: McGraw Hill, 1968.
MORGAN, R.J.; HEDÍ, L.B.; SOLIE, T.N. et al. Ketamineacepromazine as an anaesthetic agent for chinchillas (Chinchilla laniger). Lab. Anim., v.15, p.281-283, 1981.

SALMITO-VANDERLEY, C.S.B.; NEVES, M.M.; SANTANA, C.V. et al et al. Preservação do sistema genital de cabras para a avaliação em microscopia de luz. Arq. Bras. Med. Vet. Zootec., v.54, p.100-102, 2002 